\title{
Prevalence of migraine diagnosis using ID Migraine among university students in southern Turkey
}

\author{
Sebnem Bicakci · Nafiz Bozdemir · Fahri Over • \\ Esra Saatci · Yakup Sarica
}

Received: 7 December 2007/ Accepted: 25 March 2008/Published online: 22 April 2008

(C) Springer-Verlag 2008

\begin{abstract}
In this prospective study, we aimed to determine the prevalence of migraine and non-migraine headaches using a questionnaire, including ID Migraine ${ }^{\mathrm{TM}}$, for university students. The study was designed crosssectionally and a questionnaire consisting of 43 questions was applied to 1,256 students. The questionnaire consisted of questions related to demographic, social, curriculum, housing and headache characteristics of the subjects. Three-item screening questions of the ID Migraine ${ }^{\mathrm{TM}}$ test were included at the end of the questionnaire aimed at migraine diagnosis. The mean age of 1,256 students (529 females and 727 males) enrolled in this study was $21.9 \pm 2.1$ years $(17-31$ years). Migraine-type headache was detected in 265 subjects $(21.9 \%)$ based on the ID Migraine $^{\mathrm{TM}}$ evaluation. Of these, $145(54.7 \%)$ were female and $120(45.3 \%)$ were male (female/male ratio: 1.2/1). Non-migraine-type headache was identified in 864 subjects, with 357 females and 507 males. As a conclusion, ID Migraine $^{\mathrm{TM}}$ screening test might be practical and beneficial when a face-to-face interview is not possible or to predetermine the subjects for a face-to-face interview for migraine diagnosis in larger populations.
\end{abstract}

Keywords Migraine - Prevalence - University students · ID Migraine $^{\mathrm{TM}}$

S. Bicakci $(\square) \cdot$ F. Over · Y. Sarica

Department of Neurology, School of Medicine,

University of Çukurova, Adana, Turkey

e-mail: sebnemb@cu.edu.tr

N. Bozdemir · E. Saatci

Department of Family Medicine, School of Medicine,

University of Çukurova, Adana, Turkey

\section{Introduction}

Migraine and tension-type headache prevalence has been determined to be 16 (21.8\% for women and $10.9 \%$ for men) and $31.7 \%$, respectively, in Turkey based on a structured cross-sectional study for headache carried out in 13 centers with 2,007 participants. Headache profile has been defined for the first time in Turkey with this data [1]. However, structured studies in certain age and target groups are rather limited in Turkey [2-8].

Migraine prevalence in university students has been reported in a few studies $[5,7,8]$. Those studies may be limited when the negative impact of migraine on the quality of life for each age is considered. It is unequivocal that migraine data vary according to the populations and detailed evaluations are much more informative. Nonetheless, it is undeniable that a reliable and validated screening test can analyze this widespread disorder in populations quickly. These tests are advantageous and practical for clinicians to provide a preliminary data in large populations.

ID Migraine $^{\mathrm{TM}}$ (Pfizer Inc., New York, USA), which is a quick and appropriate test, has been used as a screening test in primary health services [10]. Sensitivity, specificity and positive predictive value of this test in primary care have been defined as 81,75 and $93 \%$, respectively [10]. The Turkish version of the ID Migraine ${ }^{\mathrm{TM}}$ screening test has already been validated [11, 12]. Karli et al. [12] reported $91.8 \%$ sensitivity, $63.4 \%$ specificity, $71.9 \%$ positive predictive value and $88.4 \%$ negative predictive value for ID Migraine ${ }^{\mathrm{TM}}$ in their study. It has rarely been used in large series and primarily for validation purposes $[9,13$, 14]. For example, Kim et al. [14] used ID Migraine ${ }^{\mathrm{TM}}$ for diagnostic purposes in patients with temporomandibular joint disease, whereas Karli et al. [12] validated the test in outpatient clinics. 
In this prospective study, we aimed to determine the prevalence of migraine and non-migraine headaches by using a questionnaire including ID Migraine ${ }^{\mathrm{TM}}$ for university students from various academic departments.

\section{Materials and methods}

The study was approved by the hospital ethics committee and consent was received from each subject.

\section{Sample size}

A total of 1,310 students were selected randomly among the 2003-2004 curriculum list (16,252 students in total) recieved from the university administration. The study was designed cross-sectionally and migraine prevalence was accepted as $20 \%$ in university students (worst acceptable 17-23\%) and sample size was calculated as 1,100 students with $80 \%$ power and $99 \%$ reliability range.

Of the 1,310 students, 26 refused to participate in the study and 28 were excluded due to lack of questionnaire or inappropriate internal consistency test. The ratio of involvement in the study was $95.9 \%(1,256 / 1,310)$.

Students were investigated in four groups with regard to curriculum terms. Each group consisted, as much possible, an equal number of students. Students were chosen randomly from faculties of medicine, science and social sciences of different terms to ensure standardization. Thus, students of all curriculum terms from different schools were appraised together.

First term included 1st year students of all faculties. Second term includes 3rd year medicine and dentistry students and 2 nd year of other faculties. Third term comprises 4th year medicine and dentistry students and 3rd year students of other faculties, whereas fourth term includes all seniors of all faculties.

\section{Applications}

The study was performed based on the questionnarie merely, without a face-to-face interview with the students. Due to this, other headache types according to ICHD-II were not assessed.

The questionnarie was first applied to 40 students who were not enrolled in the study and after this, it was revised into its final form. The questionnaire consisted of two parts. In the first part, questions related to social and demographic aspects of the students such as familial, economic, housing, school life, success levels, loss of term, etc., were found. The second part comprised questions related to headache. Subjects having headache were those who answered "Yes" to the questions: "Did you ever have headache in your lifetime?" and "Did you ever have headache in the last 3 months?" The final three-item screening questions of the ID Migraine $^{\mathrm{TM}}$ test were as follows (questions 41, 42 and 43 in the questionnaire): During the last 3 months, (1) did you feel nauseated or sick in your stomach with your headaches? (2) did light bother you when you had a headache (a lot more than when you do not have headaches)? (3) did your headache limit your ability to work, study or do what you needed to do for at least 1 day?

The cut-off point for a test-diagnosis of migraine headache was at least two positive responses. SPSS 14 for windows was used for data analysis [15].

\section{Results}

Of the 1,310 subjects, 1,256 students (529 female and 727 male) were enrolled in the study. Their mean age was $21.9 \pm 2.1$ years (17-31 years). Different types of headache were identified in $1,129(89.9 \%)$ subjects, whereas 127 were headache-free. Migraine-type headache was detected in 265 subjects $(21.9 \%)$ based on the ID Migrai$\mathrm{ne}^{\mathrm{TM}}$ evaluation. Table 1 displays social and demographic characteristics of the students.

Of these, $145(11.5 \%)$ were female and $120(9.6 \%)$ were male (female/male ratio: $1.2 / 1$ ). Therefore, migraine was diagnosed in 145 of 529 female subjects $(28.1 \%)$ and in 120 of 727 male subjects $(17.3 \%)$. Non-migraine type headache was identified in 864 subjects, 357 female and 507 male (Table 1).

A total of 334 students $(26.6 \%)$ were in the first term, $298(23.3 \%)$ in the second term, $312(24.8 \%)$ in the third term and $312(24.8 \%)$ in the fourth term. Migraine frequency was found to be $26.6 \%$ in the first term, being relatively higher compared to other terms, though not statistically significant. No significant difference was found in non-migraine-type headaches among different terms. Nevertheless, the frequency of non-migraine headaches (71.5\%), and the overall headache frequency $(93.5 \%)$ in the 4th term were higher than in the other terms. Gender only had a significant relation in all groups (subjects with migraine, subjects with non-migraine headache and headache free $)(P<0.005)$.

\section{Discussion}

In $21.9 \%$ of 1,256 university students, migraine diagnosis was established based on the data of the questionnaire using ID Migraine ${ }^{\mathrm{TM}}$. Female/male ratio was 1.2/1.0 $(145 / 120)$ in subjects with migraine in our study. Nonmigraine-type headache was found in $71.5 \%$ of the subjects considering the questionnaire results, whereas 
Table 1 Social and demographic characteristics of the students

\begin{tabular}{|c|c|c|c|c|}
\hline & Migraine $\%(n)$ & Non-migraine $\%(n)$ & Headache free $\%(n)$ & $P$ \\
\hline \multicolumn{5}{|l|}{ Sex } \\
\hline Females & 145 & 357 & 62 & \multirow[t]{2}{*}{$<0.001$} \\
\hline Males & 120 & 507 & 65 & \\
\hline \multicolumn{5}{|l|}{ Parents } \\
\hline Parents alive & $94(249)$ & $92.1(796)$ & $92.4(73)$ & \multirow[t]{4}{*}{0.094} \\
\hline Parents deceased & $3.4(9)$ & $6.3(54)$ & $5.1(4)$ & \\
\hline Father alive, mother deceased & $2.7(7)$ & $1.6(14)$ & $2.5(2)$ & \\
\hline Live together & $61.5(163)$ & $62.9(544)$ & $62.2(79)$ & \\
\hline \multicolumn{5}{|l|}{ Mother's education } \\
\hline Illiterate & $13.6(36)$ & $13.7(118)$ & $17.7(14)$ & \multirow[t]{3}{*}{0.539} \\
\hline Primary school & $48.3(128)$ & $50.8(439)$ & $55.7(44)$ & \\
\hline Higher education & $38.1(101)$ & $35.6(307)$ & $26.6(21)$ & \\
\hline \multicolumn{5}{|l|}{ Father's education } \\
\hline Illiterate & $3.8(10)$ & $3.4(26)$ & $5.1(4)$ & \multirow[t]{3}{*}{0.192} \\
\hline Primary school & $34.9(92)$ & $40.2(347)$ & $49.3(39)$ & \\
\hline Higher education & $61.4(162)$ & $56.4(487)$ & $45.6(36)$ & \\
\hline \multicolumn{5}{|l|}{ Housing } \\
\hline With parents & $37.9(100)$ & $40.3(348)$ & $43(34)$ & \multirow[t]{3}{*}{0.822} \\
\hline Alone & $41.7(110)$ & $40.7(352)$ & $34.2(27)$ & \\
\hline Dormitory & $14(54)$ & $15.7(164)$ & $21.5(18)$ & \\
\hline \multicolumn{5}{|l|}{ Academic department } \\
\hline Medicine & $46.8(124)$ & $52.8(456)$ & $41.8(33)$ & \multirow[t]{3}{*}{0.281} \\
\hline Social sciences & $34.7(92)$ & 31.9 (276) & $38(30)$ & \\
\hline Science & $18.5(49)$ & $15.3(132)$ & $20.3(16)$ & \\
\hline \multicolumn{5}{|l|}{ Satisfaction with school } \\
\hline Yes & $24.5(65)$ & 22.8 (207) & $25.1(31)$ & \multirow[t]{3}{*}{0.116} \\
\hline Moderate & $35.1(92)$ & $30.9(267)$ & 24.1(19) & \\
\hline No & 40.7 (108) & $45.1(390)$ & 36.7 (29) & \\
\hline \multicolumn{5}{|l|}{ Term } \\
\hline First term & $31.3(83)$ & $24.5(212)$ & $29.1(23)$ & \multirow[t]{4}{*}{0.365} \\
\hline Second term & $23.8(63)$ & $23.1(200)$ & $27.7(22)$ & \\
\hline Third term & $22.6(60)$ & $26.3(227)$ & $22.8(18)$ & \\
\hline Last term & $22.3(59)$ & $26.0(225)$ & $20.3(16)$ & \\
\hline \multicolumn{5}{|l|}{ School success } \\
\hline Perfect & $12.8(34)$ & $11.9(103)$ & $8.9(7)$ & \multirow[t]{4}{*}{0.693} \\
\hline Good & 77.4 (205) & $81.1(701)$ & $81(64)$ & \\
\hline Poor & $7.2(18)$ & $5.2(41)$ & $7.6(4)$ & \\
\hline No comment & $2.6(9)$ & 1.7 (19) & $2.5(4)$ & \\
\hline \multicolumn{5}{|l|}{ Year(s) lost } \\
\hline Before university & 43.7 (111) & $55(308)$ & $40(28)$ & \multirow[t]{2}{*}{0.953} \\
\hline After university & $6.7(8)$ & $8.1(27)$ & $6.7(2)$ & \\
\hline \multicolumn{5}{|l|}{ Income } \\
\hline $350 \$>$ & $23.5(60)$ & 24.2 (198) & $22.4(17)$ & \multirow[t]{3}{*}{0.989} \\
\hline $350-1,000 \$$ & $55.3(141)$ & $53.2(436)$ & $53.9(41)$ & \\
\hline $1,000 \$<$ & $21.2(54)$ & $22.6(185)$ & 23.7 (18) & \\
\hline Social activities & & & & \\
\hline Never or rarely & $2.6(53)$ & $2.3(210)$ & $26.6(21)$ & 0.935 \\
\hline Occasionally & $43.8(95)$ & 48.7 (442) & $46.8(37)$ & \\
\hline Frequently or always & $27.2(59)$ & $28.8(264)$ & $26.6(21)$ & \\
\hline
\end{tabular}


$6.5 \%$ of the subjects defined no headache. There are few studies on migraine in university students in Turkey [5, 7, 8] Female/male ratio was 3.4/1.0 (99/29) and 1.6/1.0 (224/138) in subjects with migraine in the first two studies, respectively. Demirkirkan et al. [5] identified migraine in $12.4 \%$ of 1,029 subjects, whereas Kurt et al. [8] reported a ratio of $17.9 \%$ in the same age group in another study.

In a recent study from our department, aimed to determine all types of headache in senior medical students, migraine was found in $24.4 \%$ ( $n$ 31/127) [7]. However, a face-to-face interview was done in 67 cases. It might be speculated that headache in cases who were invited but did not attend the study had a less negative impact on their life. Our results using ID Migraine ${ }^{\mathrm{TM}}$ were not much different from the other studies using distinct methodologies in the literature.

These ratios are higher than the ratios in the abovementioned study. In a multicenter study for headache prevalence in Turkey, migraine prevalence was found to be $20.9 \%$ in the Mediterranean region and $24.0 \%$ in the southeastern region, whereas the prevalence in Agean, Mid-Anatolian, Marmara, and Karadeniz regions was 20.6, $11.7,11.4$ and $14.7 \%$, respectively [1]. In a recent multicenter study (MIRA), including ours, migraine prevalence was found to be $24.9 \%$ in outpatient clinics irrespective of subgroup analysis [12]. Migraine prevalence was found to range between 2.4 and $40.2 \%$ in various studies based on the questionnaire in the literature. The prevalence in the studies by Mitsikostas [16], Muniz [17], Deleu [18], Demirkirkan [5], Kurt [8], Bigal 19 and Amayo 20 was 2.4, 7.58, 12.2, 12.4, 24.9, 25 and 38\%, respectively, whereas Sanvito 21 found $40.2 \%$ only in medical students of similar age. Migraine prevalence found by using ID Migraine ${ }^{\mathrm{TM}}$ in our study $(21.9 \%)$ is quite consistent with the results derived from the multicenter study in Turkey. These variations may be due to the study designs as well as the variations in the study groups. However, our own results seem to be consistent with our country's data.

On the other hand, in $71.5 \%$ of 1,256 subjects non-migraine-type headache was detected. No significant difference was found among different terms. However, the high frequency rate of migraine and non-migraine-type headache in a student population is quite interesting. As has been known, tension-type headache is the most common in the age group we have investigated [22]. In the multicenter study for headache prevalence in Turkey, frequency of tension-type headache in the Mediterranean and southeastern regions were 59 and $36.6 \%$, respectively, being consistent with the rates in our study. Regarding the latter, it is not surprising that migraine prevalence in our study is higher than in other Turkish university studies since most of the students in Cukurova University are from the Mediterranean and southeastern regions [5, 8].
Considering the stress factors for migraine in the population mentioned above in detail, gender had a statistically significant relation with migraine. On the other hand, it was quite interesting that factors such as parental health and their marital status, school success, income and social activites had no significant relation. A limitation of our study is that sensitivity and specificity ratios and predictive values could not be assessed due to its design.

As a conclusion; it is straightforward that a face-to-face verbal interview is the gold standard for migraine diagnosis and specifically designed further studies are necessary. Nevertheless, ID Migraine ${ }^{\mathrm{TM}}$, as a valid, reliable and quick screening tool in primary care migraine recognition, may encourage the clinician due to the similarities between the results of face-to-face interview and screening questionnaires in migraine studies. It would be practical and beneficial to the clinician to perform the ID Migraine in larger populations for preselection of the patients for further face-to-face interview.

\section{Conflict of interest None.}

\section{References}

1. Turkish Headache Epidemiology Study Group (1998) An epidemiologic study of headache in Turkey: a nationwide survey. Neurology 50(Suppl 4):225

2. Boru UT, Kocer A, Luleci A et al (2005) Prevalence and characteristics of migraine in women of reproductive age in Istanbul, Turkey: a population-based survey. Tohoku J Exp Med 206:1-9

3. Kececi H, Dener S (2003) Epidemiological and clinical characteristics of migraine in Sivas, Turkey. Headache 42:275-280

4. Ozge A, Bugdayci R, Sasmaz H et al (2003) The sensitivity and specificity of case criteria in diagnosis of headache: a schoolbased epidemiological study of 5,562 children in Mersin. Cephalalgia 23:138-145

5. Demirkirkan MK, Ellidokuz H, Boluk A (2006) Prevalence and clinical characteristics of migraine in university students in Turkey. Tohoku J Exp Med 208:87-92

6. Karli N, Akis N, Zarifoglu M et al (2006) Headache prevalence in adolescents aged 12 to 17: a student-based epidemiological study in Bursa. Headache 46:649-655

7. Bicakci S, Over F, Aslan K et al (2007) Headache characteristics in senior medical students in Turkey Tohoku. J Exp Med 213:277-282

8. Kurt S, Kaplan Y (2008) Epidemiological and clinical characteristics of headache in university students. Clin Neurol Neurosurg 110:46-50

9. Zarifoğlu M, Karli N, Taşkapilioğlu O et al. (2008) Can ID Migraine be used as a screening test for adolescent migraine? Cephalalgia 28:65-71

10. Lipton RB, Dodick D, Sadovsky R et al (2003) ID Migraine ${ }^{\mathrm{TM}}$ validation study. a self-administered screener for migraine in primary care: the ID Migraine ${ }^{\mathrm{TM}}$ validation study. Neurology 61:375-382

11. Siva A, Zarifoglu M, Ertas et al. (2005) Validity of the Turkish ID Migraine sreener in workers and the impact of migraine on productivity. Cephalalgia 25:H036 (abstract) 
12. Karli N, Ertas M, Baykan B et al (2007) The validation of ID Migraine screener in neurology outpatient clinics in Turkey. J Headache Pain 8:217-223

13. Brighina F, Salemi G, Fierro B et al (2005) A validation study of an Italian version of the ID Migraine ${ }^{\mathrm{TM}}$ : preliminary results. J Headache Pain 6:216-219

14. Kim ST, Kim CY (2006) Use of the ID Migraine questionnaire for migraine in TMJ and orofacial pain clinic. Headache 46:253-258

15. CDC. Epi Info Program. http://www.cdc.gov/epiinfo/

16. Mitsikostas DD, Gatzonis S, Thomas A et al (1996) An epidemiological study of headaches among medical students in Athens. Headache 36:561-564

17. Muniz R, Montiel I, Asensio M et al (1995) Prevalence of migraine in a population of university student. Rev Neurol 23:866-869
18. Deleu D, Khan MA, Humaidan H et al (2001) Prevalence and clinical characteristics of headache in medical students in Oman. Headache 41:798-804

19. Bigal ME, Bigal JM, Betti M et al. (2001) Evaluation of the impact of migraine and episodic tension-type headache on the quality of life and performance of a university student population. Headache 41:710-719

20. Amayo EO, Jowi JO, Nijeru EK (1996) Migraine headache in a group of medical students at the Kenyatta National Hospital, Nairobi. East Afr Med J 73:594-597

21. Sanvito WL, Monzillo PH, Peres MF et al. (1996) The epidemiology of migraine in medical students. Headache 36:316-319

22. Rasmussen BK, Jensen R, Olesen J (1991) A population-based analysis of the diagnostic criteria of the International Headache Society. Cephalalgia 11:129-134 